\title{
Safe maximal resection of primary cavernous sinus meningiomas via a minimal anterior and posterior combined transpetrosal approach
}

\author{
Hiroki Morisako, MD, Takeo Goto, MD, Hiroki Ohata, MD, Sachin Ranganatha Goudihalli, MS, MCh, \\ Keisuke Shirosaka, MD, and Kenji Ohata, MD
}

Department of Neurosurgery, Osaka City University Graduate School of Medicine, Osaka, Japan

\begin{abstract}
OBJECTIVE Meningiomas arising from the cavernous sinus (CS) continue to be a significant technical challenge, and resection continues to carry a relatively higher risk of neurological morbidity in patients with these lesions because of the tumor's proximity to neurovascular structures. The authors report the surgical outcomes of 9 patients with primary CS meningiomas (CSMs) that were surgically treated using a minimal anterior and posterior combined (MAPC) transpetrosal approach, and they emphasize the usefulness of the approach.
\end{abstract}

METHODS This retrospective study included 9 patients who underwent surgery for CSM treatment between 2015 and 2016 via the MAPC transpetrosal approach. Two patients were men and 7 were women, with a mean age of 58.5 years (39-72 years). Five patients (55.5\%) had undergone previous treatment. The surgical technique consisted of a temporooccipito-suboccipital craniotomy and exposure of the posterolateral part of the CS via the presigmoidal MAPC approach. After opening Meckel's cave and identifying the 3rd-5th cranial nerves in the prepontine cistern, Parkinson's triangle and supratrochlear triangles were opened. Finally, the tumor occupying the posterolateral part of the CS was removed.

RESULTS All lesions were safely and maximally removed, with preservation of external ocular movements and preoperative Karnofsky Performance Scale scores. The mean extent of resection was $77.0 \%$ (range 58.7\%-95.4\%). Six patients underwent adjuvant therapy in the form of stereotactic radiosurgery (SRS) or stereotactic radiotherapy (SRT) during the follow-up period; none of these patients experienced recurrence.

CONCLUSION The authors conclude that the MAPC transpetrosal approach could be superior to other approaches for CSMs, as it provides direct visual access to the posterolateral portion of the CS. In their experience, this approach is an alternative and better option for safe maximal resection of CSMs.

https://thejns.org/doi/abs/10.3171/2018.1.FOCUS17703

KEYWORDS transpetrosal approach; cavernous sinus; meningiomas

$\mathrm{M}$ ENINGIOMAS arising from the cavernous sinus (CS) are one of the most difficult and challenging brain tumors to remove surgically. Over the last 3 decades, with long-term outcomes of CS meningiomas (CSMs), the surgical strategy has shifted from radical resection to safe maximal removal to achieve local control of the tumor with or without additional radiation therapy. ${ }^{6,7,9-11,15-17,19,24,26,29,30,31,33,35,37}$ Several surgical approaches have been reported for CSMs, including the frontotemporal orbitozygomatic approach, frontotemporal craniotomy with or without orbital osteotomy, and extended middle fossa approach, but the optimal surgical approach remains debatable. ${ }^{6,8,14,21,26,32,35}$

The anterior and posterior combined transpetrosal approach, which consists of extensive resection of the petrosal bone to widen access to the petroclival junction with minimal retraction of the temporal lobe, has been described for the aggressive removal of petroclival lesions. . $^{1,-5,13,25,34,36}$ Despite various strategies described for this approach, it lacks popularity because of increasing rates of morbidity and mortality associated with its use in the early years..$^{1,222,27,36}$

ABBREVIATIONS CN = cranial nerve; $C S$ = cavernous sinus; $C S M=$ CS meningioma; ICA = internal carotid artery; KPS = Karnofsky Performance Scale; MAPC = minimal anterior and posterior combined; SPS = superior petrosal sinus; SRS = stereotactic radiosurgery; SRT = stereotactic radiotherapy.

SUBMITTED November 20, 2017. ACCEPTED January 29, 2018.

INCLUDE WHEN CITING DOI: 10.3171/2018.1.FOCUS17703. 
TABLE 1. Characteristics of 9 patients with primary cavernous sinus meningiomas resected via an MAPC transpetrosal approach

\begin{tabular}{|c|c|c|c|c|c|c|c|c|c|c|c|}
\hline \multirow{2}{*}{$\begin{array}{l}\text { Case } \\
\text { No. }\end{array}$} & \multirow{2}{*}{$\begin{array}{l}\text { Age (yrs), } \\
\text { Sex }\end{array}$} & \multirow[b]{2}{*}{ Previous Tx } & \multirow{2}{*}{$\begin{array}{l}\text { Preop } \\
\text { CND }\end{array}$} & \multirow{2}{*}{$\begin{array}{c}\text { Tumor } \\
\text { Diameter (mm) }\end{array}$} & \multirow{2}{*}{$\begin{array}{c}\text { EOR } \\
(\%)\end{array}$} & \multirow{2}{*}{$\begin{array}{l}\text { MIB-1 } \\
(\%)\end{array}$} & \multirow{2}{*}{$\begin{array}{c}\text { Postop Tumor } \\
\text { Vol }\left(\mathrm{cm}^{3}\right)\end{array}$} & \multirow[b]{2}{*}{ Postop CN Status } & \multirow{2}{*}{$\begin{array}{l}\text { Postop } \\
\text { RT }\end{array}$} & \multicolumn{2}{|c|}{ KPS Score } \\
\hline & & & & & & & & & & Preop & Postop \\
\hline 1 & $44, \mathrm{~F}$ & None & III & 22 & 70 & 1.3 & 1.6 & Complete recovery of III & Yes & 90 & 100 \\
\hline 2 & $39, F$ & None & II & 30 & 62 & 3.5 & 4.8 & New CND III (transient) & Yes & 90 & 90 \\
\hline 3 & $61, \mathrm{M}$ & None & None & 36 & 84 & 2.0 & 2 & No new CND & No & 100 & 100 \\
\hline 4 & $63, \mathrm{M}$ & None & II, III, \& VI & 36 & 92 & 0.5 & 1.1 & Partial improvement of VI & No & 90 & 90 \\
\hline 5 & $68, \mathrm{~F}$ & 1 op, 1 SRS & V \& VI & 35 & 88 & 7.3 & 2 & Partial improvement of $\mathrm{V}$ & Yes & 80 & 80 \\
\hline 6 & $69, F$ & $\begin{array}{c}1 \text { op, } 1 \text { SRS } \\
1 \text { SRT }\end{array}$ & III, V, \& VI & 30 & 59 & 2.0 & 5.9 & No new CND & No & 80 & 80 \\
\hline 7 & $44, \mathrm{~F}$ & 1 op & II \& V & 63 & 95 & 2.5 & 1.7 & No new CND & Yes & 70 & 70 \\
\hline 8 & $72, \mathrm{~F}$ & 3 ops & $\|\&\| \|$ & 45 & 84 & 9.0 & 8 & No new CND & Yes & 70 & 70 \\
\hline 9 & $67, \mathrm{~F}$ & 4 ops & $\begin{array}{l}\text { II, III, IV, } \\
\text { V \& VI }\end{array}$ & 39 & 59 & 2.0 & 12.3 & No new CND & Yes & 80 & 80 \\
\hline
\end{tabular}

$\mathrm{CND}=\mathrm{CN}$ deficit; $\mathrm{EOR}=$ extent of resection; $\mathrm{RT}=$ radiotherapy; $\mathrm{Tx}=$ treatment.

To avoid the problems associated with this approach, we have modified the technique by minimizing the petrosectomy, making it what we call the minimal anterior and posterior combined (MAPC) transpetrosal approach. ${ }^{18} \mathrm{We}$ emphasize the fact that this approach offers a wider exposure of the posterolateral CS area and a unique view of the $\mathrm{CS}$ with inferior-to-superior and posterior-to-anterior trajectories, with a lower risk of injury to the neurovascular structures around it.

In this study, we describe the surgical technique and outcomes after performing the MAPC transpetrosal approach for primary CSMs.

\section{Methods}

Between June 2015 and November 2016, 9 patients underwent surgery via the MAPC transpetrosal approach for CSMs at the Osaka City University Hospital. Two patients were men, and 7 were women; the mean patient age was 58.5 years (range $39-72$ years). Five tumors $(55.5 \%)$ were recurrences that had been previously treated either with surgery or radiation therapy (Table 1).

All patients underwent preoperative CT scanning, MRI, and angiography. The mean tumor diameter was $37.3 \mathrm{~mm}$ (range $22-63 \mathrm{~mm}$ ). Neuroradiologists independently evaluated the extent of tumor resection by comparing the pre- and postoperative enhanced MR images that were obtained within 1 week after surgery. For each patient, the medical records were retrospectively reviewed to evaluate the status of the cranial nerves (CNs) and Karnofsky Performance Scale (KPS) score.

\section{Surgical Technique}

Much of the following descriptions of patient positioning and skin incision, craniotomy, petrosectomy, dural opening, and reconstruction of the skull base were previously published in our earlier study. ${ }^{18,25}$

\section{Patient Positioning and Skin Incision}

The patient was placed in a semiprone park-bench po- sition. The head was fixed using 3-point fixation with the head rotated and vertex down to keep the temporal side of the head in the horizontal plane. The skin incision began at the upper margin of the zygomatic arch anterior to the tragus, turned 2-3 cm above the ear, and then descended behind the posterior margin of the mastoid process. After the skin flap was raised, a temporalis fascia pericranial flap with a pedicle of the sternocleidomastoid muscle was used for the dural reconstruction at the end of surgery to prevent postoperative CSF leakage.

\section{Craniotomy}

A temporo-occipito-suboccipital craniotomy was performed prior to the mastoidectomy. Burr holes were placed at 6 points, including anatomical landmarks, to avoid injury to the sigmoid sinus. The first burr hole was made at the asterion, the second at the intersection of the supramastoid crest with the squamous suture, the third at the mastoid emissary foramen, the fourth at the root of the zygoma, and the fifth and sixth at the anterior and posterior aspects of the temporal bone, respectively. The first 3 burr holes are very important, as they are close to the sinus and have to be carefully drilled. The first burr hole is usually made just above the lateral end of the transverse sinus; the second, just anterior to the transverse-sigmoid sinus junction; and the third, a few millimeters medial to the posterior edge of the sigmoid sinus.

\section{Minimum Petrosectomy}

After the temporo-occipito-suboccipital craniotomy was completed, the outer cortical bone of the mastoid portion of the temporal bone was removed as a thin, triangular plate, a procedure referred to as a cosmetic mastoidectomy. The procedure is not essential and is skipped in cases in which the groove of the sigmoid sinus is too large. At this point, the sigmoid sinus and transverse sinus-sigmoid sinus junction were safely exposed. Dural dissection from the petrous and mastoid portions of the temporal bone was then done for a safe and swift petrosectomy. In the middle fossa, the dura mater over the temporal base was 
gently reflected to fully expose the entire course of the petrous ridge and apex by cutting the middle meningeal artery and dissecting the greater superficial petrosal nerve. In the posterior fossa, the presigmoid dura was carefully dissected from the posterior surface of the petrous portion of the temporal bone, and the entrance of the internal auditory canal was exposed epidurally by cutting the endolymphatic sac. After the dural dissection was complete, bony work encompassing minimal petrosectomy was performed. During drilling, care was taken to keep the membranous labyrinths of the semicircular canals intact for hearing preservation. The amount of petrous bone drilled was minimal and therefore required less time. Drilling of the petrous ridge is one of the key steps in obtaining a surgical corridor along its axis, and the amount of ridge drilled was minimal as well.

\section{Dural Opening}

The middle fossa dura was opened along the inferior temporal lobe toward the superior petrosal sinus (SPS). The subtemporal dural incision was made as far anterior as possible, and its medial extent ran along the lateral margin of Meckel's cave. The presigmoid dura was opened along the drilled petrosal portion of the temporal bone as far anterior as possible, and the drainage of the petrosal vein into the SPS was inspected. The SPS was divided by clips at a point anterior to the drainage point of the petrosal vein into the SPS to preserve its venous drainage. The tentorium was cut completely to inspect the trochlear nerve and its entrance into the intradural part.

\section{Intradural Procedure}

After superior retraction of the temporal lobe and medial mobilization of the sigmoid sinus, the portion of the tumor occupying Meckel's cave was removed first. Once the superior wall of Meckel's cave was opened, the trigeminal nerve was mobilized laterally to expose the posterolateral part of the CS and increase the working space. The portion of the tumor extending in the anterior side of the brainstem was removed, and Parkinson's triangle and the supratrochlear triangles were opened in a posterior-to-anterior direction in a step-wise manner. The dura along the tentorial edge at the entrance of the trochlear nerve was cut more anteriorly to perform additional internal decompression of the tumor occupying the posterior portion of the CS. Then, the superior part of the tumor was resected between the trochlear and oculomotor nerves. After opening the porus oculomotorius, the residual tumor inside the oculomotor cistern was removed as much as possible, and the oculomotor nerve was decompressed. Pulsation of a $\mathrm{C}_{5}$ segment of the internal carotid artery (ICA) was identified on the inferomedial side, and bleeding from branches of the ICA, mainly the inferolateral trunk and meningohypophyseal trunk, was coagulated so that the carotidoculomotor membrane could be reached. Safe maximal resection of the tumor was achieved with a lower risk of injury to the surrounding vital structures (Fig. 1).

\section{Reconstruction of the Skull Base}

All opened mastoid air cells were sealed with abdomi-

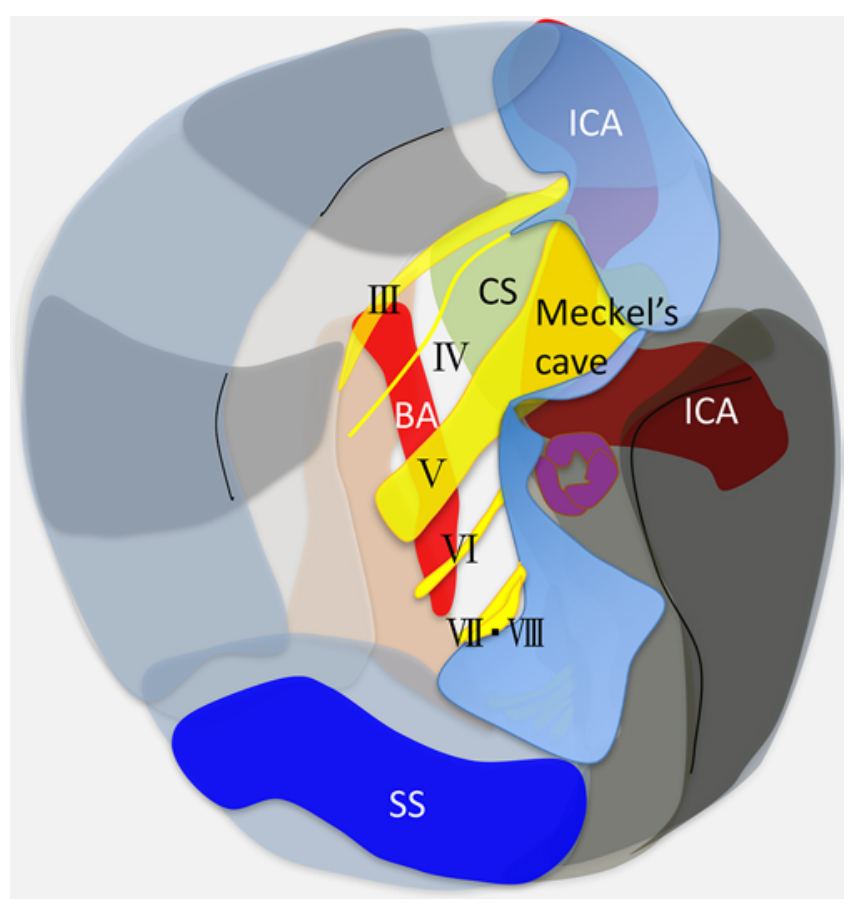

FIG. 1. Illustration demonstrating the wide exposure and the inferior-tosuperior and posterior-to-anterior trajectory for the CS area obtained by the MAPC approach. BA = basilar artery; SS = sigmoid sinus; III = oculomotor nerve; IV = trochlear nerve; $\mathrm{V}=$ trigeminal nerve; $\mathrm{VI}=$ abducent nerve; $\mathrm{VII}=$ facial nerve; $\mathrm{VIII}=$ acoustic nerve.

nal fat soaked in fibrin glue, and then the mastoid and petrous portions of the temporal bone and dural defect were entirely covered with the harvested temporal fascia pericranial flap. The lumbar drain was left open for approximately 3 days to prevent CSF leakage.

\section{Illustrative Case \\ Case 1}

A 44-year-old woman presented with a 3-month history of diplopia on left lateral gaze and ptosis of the right eye. Preoperative MRI demonstrated a heterogeneously enhanced lesion in the right cavernous area (Fig. 2A and B), extending posteriorly to the brainstem. The lesion was approached through the MAPC transpetrosal approach (Fig. 3A-E). After opening Meckel's cave, the trigeminal nerve was identified, and the tumor inside Meckel's cave and along its superior wall was removed (Fig. $3 \mathrm{~F}$ and G). The dura at the entrance of the trochlear nerve was cut anteriorly along the tentorial edge, and additional internal decompression of the tumor occupying the posterior part of the CS was performed (Fig. 3H). After this step, superior extension of the tumor between the trochlear and the oculomotor nerve was removed (Fig. 3I). The porus oculomotorius was opened (Fig. 3J), and the residual tumor inside the oculomotor cistern was removed maximally to decompress the oculomotor nerve (Fig. 3K and L). The postoperative course was uneventful, and the oculomotor palsy improved. The patient underwent stereotactic radiotherapy (SRT) during follow-up, and the residual tumor was well controlled (Fig. 2C and D). 


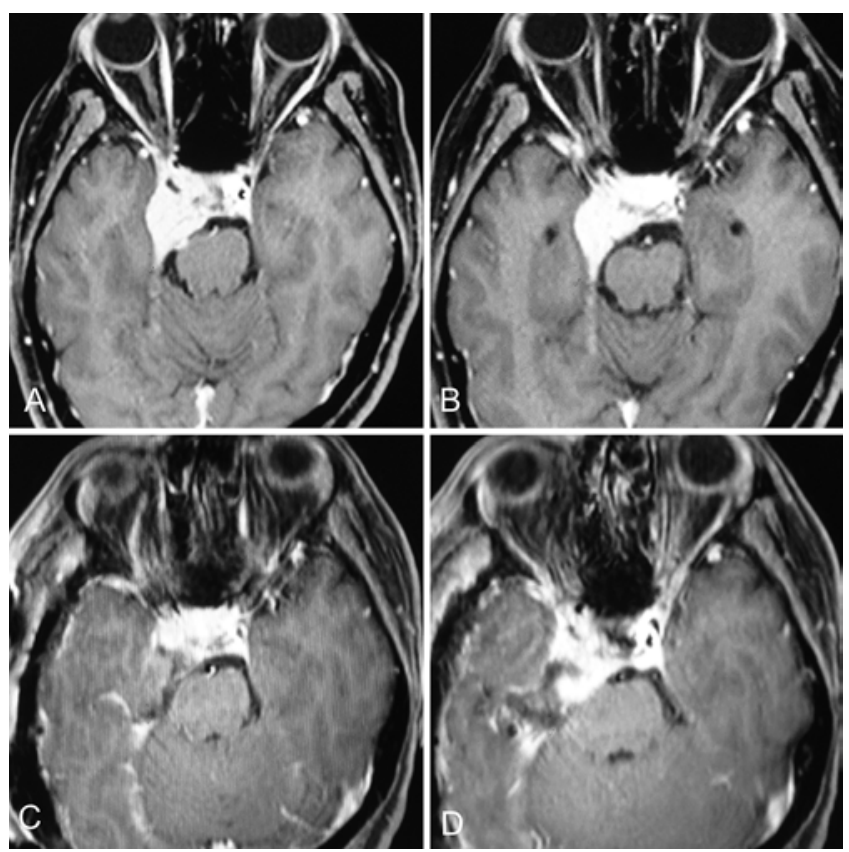

FIG. 2. Case 1. Axial Gd-enhanced T1-weighted MR images. A and B: Preoperative images showing the tumor occupying the CS on the right side and extending posteriorly around the brainstem. C and D: Postoperative images showing removal of the tumor that had occupied the posterior CS.

\section{Results}

A summary of the clinical course of the 9 patients treated using the MAPC transpetrosal approach is shown in Table 1. The mean preoperative tumor volume was 21.4 $\mathrm{cm}^{3}$ (range 5.3-49.4 $\mathrm{cm}^{3}$ ). The mean extent of tumor resection was $77.0 \%$ (range $58.7 \%-95.4 \%$ ), and the mean postoperative tumor volume was $4.3 \mathrm{~cm}^{3}$ (range $1.1-12.3 \mathrm{~cm}^{3}$ ).

There were no deaths related to the procedure. None of the patients developed postoperative CSF leak or infection. Six patients underwent stereotactic radiosurgery (SRS) or SRT during follow-up; none of these patients experienced recurrence.

One patient (case 1) exhibited improvement in her oculomotor nerve palsy, and another patient (case 4) showed partial improvement in his abducens nerve palsy. One patient (case 2) had a transient oculomotor nerve palsy, which resolved within 3 months. The remaining patients did not exhibit any new $\mathrm{CN}$ deficits, and the preoperative KPS score was preserved in all patients (Table 1).

\section{Morphological Study}

We studied the MAPC transpetrosal approach using a cadaveric head. Under the microscope, the posterolateral portion of the CS was exposed (Fig. 4A). Meckel's cave was opened to identify the trigeminal nerve. Then, the lateral wall of the $\mathrm{CS}$, formed by the reticular layer between the trochlear nerve and V1 segment of the trigeminal nerve, was cut to expose Parkinson's triangle. Then, the supratrochlear triangle was opened, and the oculomotor sheath extending from the porus oculomotorius to the carotid-oculomotor membrane was cut to expose the ocu- lomotor trigone. Some of the pictures of cadaveric dissection are shown, among which are the posterolateral part of the CS (Fig. 4B), the distance between the porus oculomotorius and the carotid-oculomotor membrane $(8 \mathrm{~mm}$ in this study), and identification of the $\mathrm{C}_{4}-\mathrm{C}_{5}$ portion of the ICA and abducens nerve after removal of the inferomedial wall of Meckel's cave (Fig. 4C and D).

\section{Discussion}

\section{Concept of the MAPC Transpetrosal Approach for Primary CSMs}

The CS extends from the superior orbital fissure anteriorly to the petrous apex posteriorly, and it is bordered by the sella medially and middle fossa laterally. The CS forms the posterior margin of the superior orbital fissure, which is located below the anterior clinoid process, and its posterior wall extends from the lateral edge of the dorsum sellae to the medial margin of the trigeminal impression and Meckel's cave. The posterior portion of the roof is formed by the dura, which forms the oculomotor trigone. The oculomotor trigone, through which the oculomotor nerve enters the roof of the CS, is located between the anterior and posterior petroclinoid and the interclinoid folds. The oculomotor nerve is wrapped with oculomotor sheath at the porus oculomotorius, and there is a small arachnoid space. The dura that lines the lower margin of the anterior clinoid process and extends medially above the oculomotor nerve to the ICA and from the proximal dural ring is referred to as the carotid-oculomotor membrane.

Many authors have developed techniques for approaching the CS region via the frontotemporal route to improve resection and decrease patient morbidity. ${ }^{8,21,32}$ Over the past 2 decades, many variations of frontotemporal approaches, including a frontotemporal orbitozygomatic approach, a frontotemporal craniotomy with orbital osteotomy, an extradural approach, and a middle fossa approach, have been used to resect CS tumors. It is well known that surgical complications are correlated with the extent of tumor resection. The frontotemporal orbitozygomatic approach allows a unique anterolateral projection to the CS, with a wider working angle and space, and thus a lesser amount of brain retraction is required. However, due to its complex anatomy, safe entry points are limited to the anterolateral region of the CS, which can be simulated to the apex of a pyramid (Fig. 5, arrow a).

On the other hand, the posterior end of the CS behaves like the base of a pyramid, allowing wider entry between the CNs. Through the MAPC transpetrosal approach, most $\mathrm{CNs}$ were identified in the pontine cistern before the tumor resection, and the $\mathrm{C}_{4}-\mathrm{C}_{5}$ portion of the ICA and the abducens nerve were identified running behind the inferomedial wall of Meckel's cave (Fig. 5, arrow b). Martins et al. reported that the width of the oculomotor cistern was maximal at the porus oculomotorius and averaged $5.5 \mathrm{~mm}$ (range 3.0-9.2 $\mathrm{mm}$ ), and the average length of the oculomotor cistern was $6.5 \mathrm{~mm}$ (range $3.0-11.0 \mathrm{~mm}$ ). ${ }^{23}$ Ono et al. measured the distance of the carotid artery to the oculomotor nerve and found it to range from 3.0 to 10.4 $\mathrm{mm},{ }^{28}$ which correlates with the distance between the porus oculomotorius and carotid-oculomotor membrane 

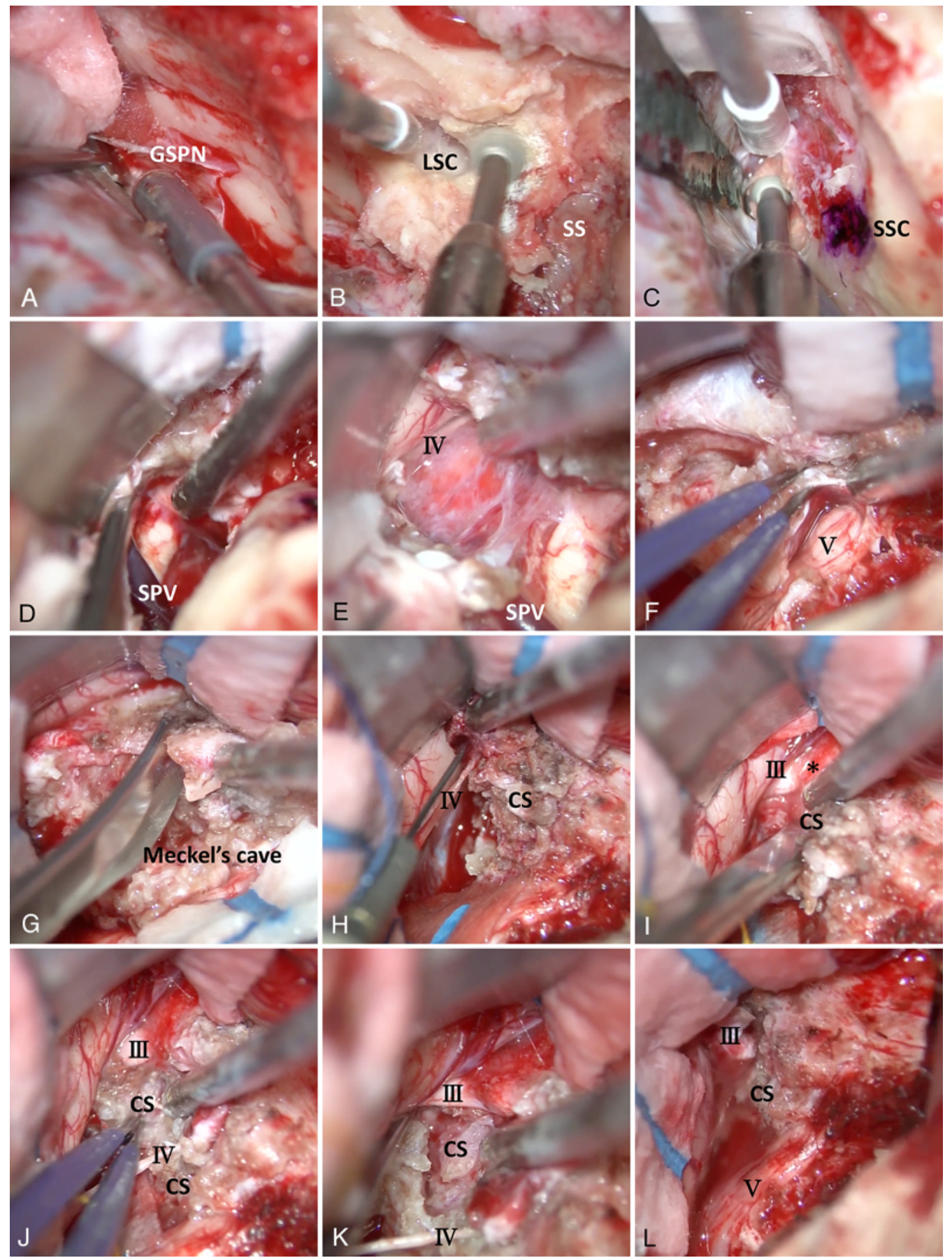

FIG. 3. Case 1. Intraoperative photographs. A: At the middle fossa, the temporal dura mater is retracted, and the anterior surface of the petrous ridge is exposed entirely after cutting the middle meningeal artery and dissecting the greater superficial petrosal nerve (GSPN). B: After dissection of the sigmoid sinus at the posterior fossa, the posterior surface of the petrous ridge is exposed, and the mastoid antrum is opened. The semicircular canals are not drilled in order to preserve hearing. C: A small amount of the petrous bone is drilled out along the petrous ridge to obtain a unique inferior-to-superior and posterior-to-anterior surgical corridor. D: The SPS is cut at the anterior part of the connective point of superior petrosal vein and SPS to keep venous drainage intact. E: After confirmation of the dural entrance of the trochlear nerve, the tentorium is cut. F: After superior retraction of the temporal lobe, the tumor occupying Meckel's cave is removed. G: The superior wall of Meckel's cave is removed. H: The dural entrance of the trochlear nerve is cut more anteriorly along with the tentorial edge, and the posterolateral cavernous area is widely exposed. I: The oculomotor nerve is compressed by the tumor at the porus oculomotorius $\left(^{*}\right)$. J: After opening the porus oculomotorius, the superior part of the tumor can be resected between the trochlear nerve and the oculomotor nerve. $\mathrm{K}$ and L: The residual tumor inside the posterior CS is removed as much as possible to decompress the oculomotor nerve. LSC = lateral semicircular canal; SPV = superior petrosal vein; SSC = superior semicircular canal. 

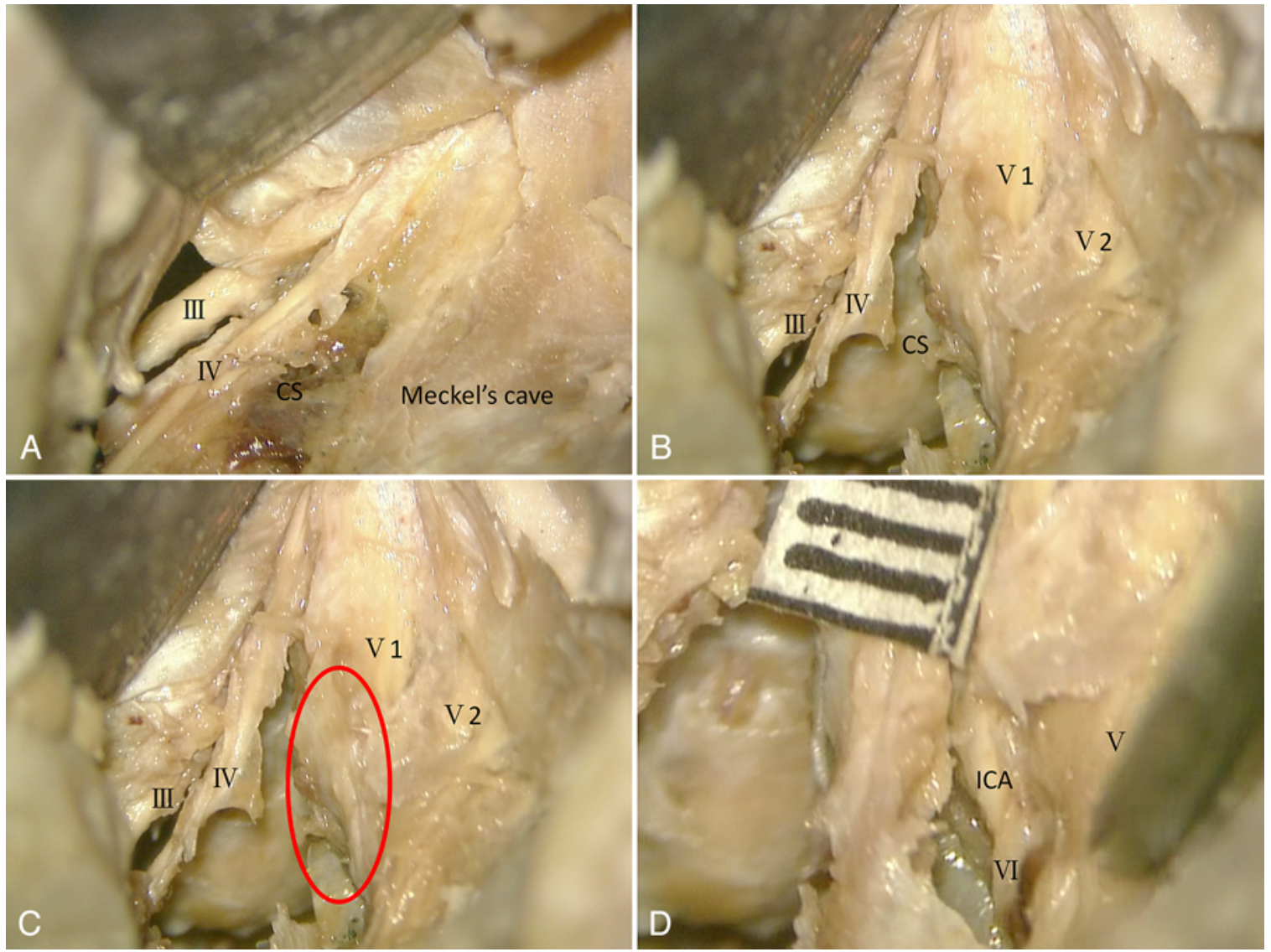

FIG. 4. Cadaveric dissection of the CS area via an MAPC transpetrosal approach. A: After the approach is performed, the CS and Meckel's cave are exposed. B: After removing the superior wall of Meckel's cave, Parkinson's triangle and the supratrochlear triangles are opened through an inferior-to-superior and posterior-to-anterior surgical corridor. C and D: The cavernous portion of the ICA and abducens nerve are identified after removal of the inferomedial wall of Meckel's cave.

measured in the cadaveric study $(8 \mathrm{~mm})$. Thus, the CS can be accessed safely after cutting the oculomotor trigone along the oculomotor sheath with an inferior-to-superior and posterior-to-anterior trajectory, followed by maximal decompression of the CSMs through the posterior and lateral walls of the CS, with less risk of injury to the ICA and CNs. The MAPC transpetrosal approach for CSMs is based on this anatomical concept. Although only a few patients have been treated using this approach, postoperative preservation of $\mathrm{CN}$ function appears to be superior to that achieved using other surgical modalities.

\section{Treatment Strategy of Primary CSMs}

In the 1990s, when skull base approaches flourished, many experts attempted total resection of CSMs through various cavernous triangles as described in the literature. ${ }^{7,10,14}$ Surgical results were not satisfactory with respect to functional preservation of CNs running in and around the CS. Subtotal resection followed by adjuvant therapy with either SRS or SRT has been regarded as an acceptable treatment that preserves $\mathrm{CN}$ functions. . $^{6,20,24,26,30,31,35}$ An ideal surgical management of CSMs is a partial resection with the purpose of decompression of the brainstem, CNs, or optic pathway. Aggressive removal of the CSMs with bypass of the external and internal carotid arteries is not a common surgical management. $6,31,37$

Recent reports on CSM treatment have recommend safe, maximal resection with adjuvant radiation therapy rather than complete tumor removal. ${ }^{6,20,24,26,30,31,35} \mathrm{Hafez}$ et al. evaluated the results of stereotactic Gamma Knife radiosurgery in symptomatic benign CSMs and showed a tumor control rate of $96 \%$ at the 3-year follow-up period with a mean pretreatment tumor volume of $5.7 \mathrm{~cm}^{3}$ (range $\left.1.8-12.4 \mathrm{~cm}^{3}\right) .^{12}$ Maruyama et al. treated their patients with radiosurgery alone when there was distance between tumors and the optic pathway or brainstem. They used a combination of surgery and radiosurgery for CSMs when the tumors were attached to or compressing the optic pathway and brainstem, were larger than $3 \mathrm{~cm}$ in diameter, and extended into the multiple cranial fossae. They achieved an actuarial tumor control rate of $94.1 \%$ at the 5-year followup. ${ }^{24}$ In the current study, the mean extent of resection was $77.0 \%$, and the residual tumor volume was less than 12.4 $\mathrm{cm}^{3}$ in all patients, with no mortality or severe morbidity. We think that maximal safe resection through the MAPC transpetrosal approach is a good surgical option for the treatment of CSMs. Adjuvant treatment with either SRS or SRT can be selected for residual tumor or any recur- 


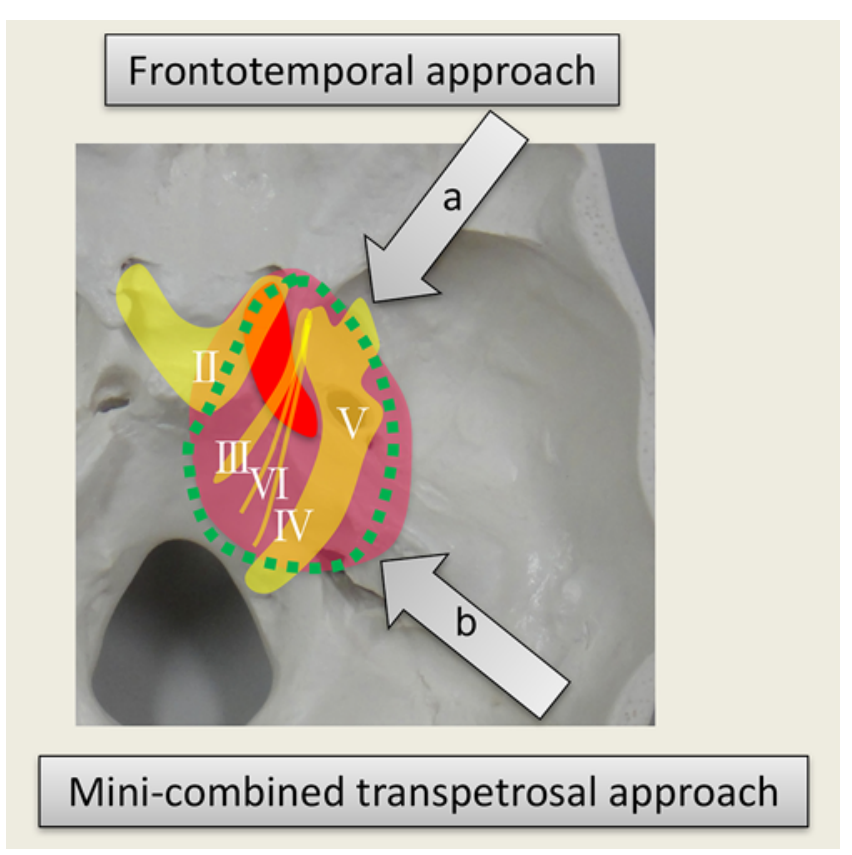

FIG. 5. Illustration demonstrating the surgical corridors obtained by the frontotemporal approach (a) and MAPC transpetrosal approach (b) to the CS lesion. By using a frontotemporal approach, the apex of the pyramid is exposed with limited safe entry points through an anterolateral projection. The base of the pyramid is exposed with wider safe entry points via an MAPC transpetrosal approach.

rence. Of course, SRS or SRT is the desirable treatment for asymptomatic, small tumors. However, aggressive tumor resection should be considered for young patients with a short clinical history, even if the tumor size is small. For CSMs that extend to the sphenoclinoidal area anteriorly or compress the optic nerve medially, the frontotemporal approach or endonasal endoscopic approach should be considered as the first choice based on tumor location.

\section{Conclusions}

We describe in detail the MAPC transpetrosal approach for the treatment of primary CSMs. This approach provides safe and wider access to the posterior portion of the CS, taking care of the CNs and aiding in maximal safe resection of the intracavernous portion of the tumor, with postoperative preservation of $\mathrm{CN}$ function. Maximal resection using the MAPC transpetrosal approach, followed by timely SRS or SRT for large CSMs, is a safe and effective surgical alternative, with an aim of adequate tumor control in long-term follow-up.

\section{References}

1. Al-Mefty O, Fox JL, Smith RR: Petrosal approach for petroclival meningiomas. Neurosurgery 22:510-517, 1988

2. Bricolo AP, Turazzi S, Talacchi A, Cristofori L: Microsurgical removal of petroclival meningiomas: a report of 33 patients. Neurosurgery 31:813-828, 1992

3. Chanda A, Nanda A: Partial labyrinthectomy petrous apicectomy approach to the petroclival region: an anatomic and technical study. Neurosurgery 51:147-160, 2002
4. Cho CW, Al-Mefty O: Combined petrosal approach to petroclival meningiomas. Neurosurgery 51:708-718, 2002

5. Couldwell WT, Fukushima T, Giannotta SL, Weiss MH: Petroclival meningiomas: surgical experience in 109 cases. J Neurosurg 84:20-28, 1996

6. Couldwell WT, Kan P, Liu JK, Apfelbaum RI: Decompression of cavernous sinus meningioma for preservation and improvement of cranial nerve function. Technical note. J Neurosurg 105:148-152, 2006

7. Cusimano MD, Sekhar LN, Sen CN, Pomonis S, Wright DC, Biglan AW, et al: The results of surgery for benign tumors of the cavernous sinus. Neurosurgery 37:1-10, 1995

8. D'Ambrosio AL, Mocco J, Hankinson TC, Bruce JN, van Loveren HR: Quantification of the frontotemporal orbitozygomatic approach using a three-dimensional visualization and modeling application. Neurosurgery 62 (3 Suppl 1):251-261, 2008

9. De Jesús O, Sekhar LN, Parikh HK, Wright DC, Wagner DP: Long-term follow-up of patients with meningiomas involving the cavernous sinus: recurrence, progression, and quality of life. Neurosurgery 39:915-920, 1996

10. DeMonte F, Smith HK, al-Mefty O: Outcome of aggressive removal of cavernous sinus meningiomas. J Neurosurg 81:245-251, 1994

11. Dufour H, Muracciole X, Métellus P, Régis J, Chinot O, Grisoli F: Long-term tumor control and functional outcome in patients with cavernous sinus meningiomas treated by radiotherapy with or without previous surgery: is there an alternative to aggressive tumor removal? Neurosurgery 48:285-296, 2001

12. Hafez RF, Morgan MS, Fahmy OM: Stereotactic Gamma Knife surgery safety and efficacy in the management of symptomatic benign confined cavernous sinus meningioma. Acta Neurochir (Wien) 157:1559-1564, 2015

13. Hakuba A, Nishimura S, Jang BJ: A combined retroauricular and preauricular transpetrosal-transtentorial approach to clivus meningiomas. Surg Neurol 30:108-116, 1988

14. Hakuba A, Tanaka K, Suzuki T, Nishimura S: A combined orbitozygomatic infratemporal epidural and subdural approach for lesions involving the entire cavernous sinus. J Neurosurg 71:699-704, 1989

15. Klink DF, Sampath P, Miller NR, Brem H, Long DM: Longterm visual outcome after nonradical microsurgery patients with parasellar and cavernous sinus meningiomas. Neurosurgery 47:24-32, 2000

16. Knosp E, Perneczky A, Koos WT, Fries G, Matula C: Meningiomas of the space of the cavernous sinus. Neurosurgery 38:434-444, 1996

17. Kotapka MJ, Kalia KK, Martinez AJ, Sekhar LN: Infiltration of the carotid artery by cavernous sinus meningioma. J Neurosurg 81:252-255, 1994

18. Kunihiro N, Goto T, Ishibashi K, Ohata K: Surgical outcomes of the minimum anterior and posterior combined transpetrosal approach for resection of retrochiasmatic craniopharyngiomas with complicated conditions. J Neurosurg 120:1-11, 2014

19. Larson JJ, van Loveren HR, Balko MG, Tew JM Jr: Evidence of meningioma infiltration into cranial nerves: clinical implications for cavernous sinus meningiomas. J Neurosurg 83:596-599, 1995

20. Lee JY, Niranjan A, McInerney J, Kondziolka D, Flickinger JC, Lunsford LD: Stereotactic radiosurgery providing longterm tumor control of cavernous sinus meningiomas. J Neurosurg 97:65-72, 2002

21. Lemole GM Jr, Henn JS, Zabramski JM, Spetzler RF: Modifications to the orbitozygomatic approach. Technical note. J Neurosurg 99:924-930, 2003

22. Little KM, Friedman AH, Sampson JH, Wanibuchi M, Fukushima T: Surgical management of petroclival meningiomas: 
defining resection goals based on risk of neurological morbidity and tumor recurrence rates in 137 patients. Neurosurgery 56:546-559, 2005

23. Martins C, Yasuda A, Campero A, Rhoton AL Jr: Microsurgical anatomy of the oculomotor cistern. Neurosurgery 58 (4 Suppl 2):ONS-220-ONS-228, 2006

24. Maruyama K, Shin M, Kurita H, Kawahara N, Morita A, Kirino T: Proposed treatment strategy for cavernous sinus meningiomas: a prospective study. Neurosurgery 55:10681075,2004

25. Morisako H, Goto T, Ohata K: Petroclival meningiomas resected via a combined transpetrosal approach: surgical outcomes in 60 cases and a new scoring system for clinical evaluation. J Neurosurg 122:373-380, 2015

26. Nanda A, Thakur JD, Sonig A, Missios S: Microsurgical resectability, outcomes, and tumor control in meningiomas occupying the cavernous sinus. J Neurosurg 125:378-392, 2016

27. Natarajan SK, Sekhar LN, Schessel D, Morita A: Petroclival meningiomas: multimodality treatment and outcomes at long-term follow-up. Neurosurgery 60:965-981, 2007

28. Ono M, Ono M, Rhoton AL Jr, Barry M: Microsurgical anatomy of the region of the tentorial incisura. J Neurosurg 60:365-399, 1984

29. O'Sullivan MG, van Loveren HR, Tew JM Jr: The surgical resectability of meningiomas of the cavernous sinus. Neurosurgery 40:238-247, 1997

30. Pamir MN, Kiliç T, Bayrakli F, Peker S: Changing treatment strategy of cavernous sinus meningiomas: experience of a single institution. Surg Neurol 64 (Suppl 2):S58-S66, 2005

31. Pichierri A, Santoro A, Raco A, Paolini S, Cantore G, Delfini $\mathrm{R}$ : Cavernous sinus meningiomas: retrospective analysis and proposal of a treatment algorithm. Neurosurgery 64:10901101, 2009

32. Seçkin H, Avci E, Uluç K, Niemann D, Başkaya MK: The work horse of skull base surgery: orbitozygomatic approach. Technique, modifications, and applications. Neurosurg Focus 25(6): E4, 2008

33. Sekhar LN, Patel S, Cusimano M, Wright DC, Sen CN, Bank WO: Surgical treatment of meningiomas involving the cav- ernous sinus: evolving ideas based on a ten year experience. Acta Neurochir Suppl 65:58-62, 1996

34. Sekhar LN, Schessel DA, Bucur SD, Raso JL, Wright DC: Partial labyrinthectomy petrous apicectomy approach to neoplastic and vascular lesions of the petroclival area. Neurosurgery 44:537-552, 1999

35. Sindou M, Wydh E, Jouanneau E, Nebbal M, Lieutaud T: Long-term follow-up of meningiomas of the cavernous sinus after surgical treatment alone. J Neurosurg 107:937-944, 2007

36. Spetzler RF, Daspit CP, Pappas CT: The combined supra- and infratentorial approach for lesions of the petrous and clival regions: experience with 46 cases. J Neurosurg 76:588-599, 1992

37. Sughrue ME, Rutkowski MJ, Aranda D, Barani IJ, McDermott MW, Parsa AT: Factors affecting outcome following treatment of patients with cavernous sinus meningiomas. J Neurosurg 113:1087-1092, 2010

\section{Disclosures}

The authors report no conflict of interest concerning the materials or methods used in this study or the findings specified in this paper.

\section{Author Contributions}

Conception and design: Morisako, Goto. Acquisition of data: Morisako, H Ohata, Shirosaka. Analysis and interpretation of data: Morisako. Drafting the article: Morisako. Critically revising the article: Morisako, Goudihalli. Reviewed submitted version of manuscript: Morisako, Goto, Goudihalli. Approved the final version of the manuscript on behalf of all authors: Morisako. Administrative/technical/material support: Goto. Study supervision: Goto, K Ohata.

\section{Correspondence}

Hiroki Morisako: Osaka City University Graduate School of Medicine, Osaka, Japan. hmorisako@med.osaka-cu.ac.jp. 